\title{
Alobar holoprosencephaly and Trisomy 13 (Patau syndrome)
}

\author{
Andressa Dias Costa ${ }^{a}$, Regina Schultza ${ }^{a}$ Sérgio Rosemberga
}

Costa AD, Schultz R, Rosemberg S. Alobar holoprosencephaly and Trisomy 13 (Patau syndrome). Autopsy Case Rep [Internet]. 2013;3(2):5-10. http://dx.doi.org/10.4322/acr.2013.012

\section{ABSTRACT}

Holoprosencephaly (HPE) is a congenital defect of the brain, median structures, and face resulting from an incomplete cleavage of the primitive brain during early embryogenesis. The authors report a case of trisomy 13 syndrome diagnosed at prenatal follow up. The preterm newborn lived only 5 hours, and died because of severe respiratory failure. The autopsy findings disclosed facial, skull, limbs, cardiac, and cerebral malformations. Among the latter, the presence of alobar HPE, the central theme of this report, was evident. The most common nonrandom chromosomal abnormality in patients with HPE is trisomy 13. The most severe variant, namely alobar HPE, is shown in this case report. Discussion on this severe anomaly, along with the case report with details of Patau's syndrome, is the goal of this report.

Keywords: Holoprosencephaly; Nervous System Malformations; Patau syndrome; Autopsy.

\section{CASE REPORT}

A Caucasian girl was born prematurely through vaginal delivery at an ultrasonographic gestational age of 31 weeks and 6 days, and weighed $1150 \mathrm{~g}$, with an Apgar score of 4/4/5, at $1 / 5 / 10$ minutes. This was the first pregnancy of a 21-year-old mother who was hitherto healthy. She denied alcohol, other drug consumption, and smoking. Serologic tests were undertaken during prenatal examination and were negative for syphilis, HIV, hepatitis B and C, and rubella. A karyotype, performed with amniotic fluid cells, resulted in $47 X X+13$ (female karyotype and trisomy13). Immediately after delivery, the newborn presented respiratory distress requiring high titers of oxygen supplementation, progressing to bradycardia and apnea, and died 5 hours after birth.

\section{AUTOPSY}

The external examination depicted proboscis, microcephaly, ocular hypotelorism, reduced palpebral fissures, microstomia, micrognathia, and low-set ears (Figures 1A). On the scalp, an exposed anterior fontanelle caused by aplasia cutis, which measured $3.5 \times 3.0 \mathrm{~cm}$, was noticed (Figure 1B). The limbs exhibited right hand-camptodactyly, prominent heels (Figure 1C) and left foot polydactyly (Figure 1D).

On opening the skull, alobar HPE was evidenced (Figure 2). The microscopic examination showed gliomeningeal ectopy and migratory defect.

At the thoracic cavity overture, followed by cardiac dissection, hypoplastic left heart syndrome

a Department of Pathology - Hospital das Clínicas - Faculdade de Medicina - Universidade de São Paulo, São Paulo/SP - Brazil.

Copyright $\odot 2013$ Autopsy and Case Reports - This is an Open Access article distributed of terms of the Creative Commons Attribution NonCommercial License (http://creativecommons.org/licenses/by/3.0/) which permits unrestricted non-commercial use, distribution, and reproduction in any médium provided article is properly cited. 


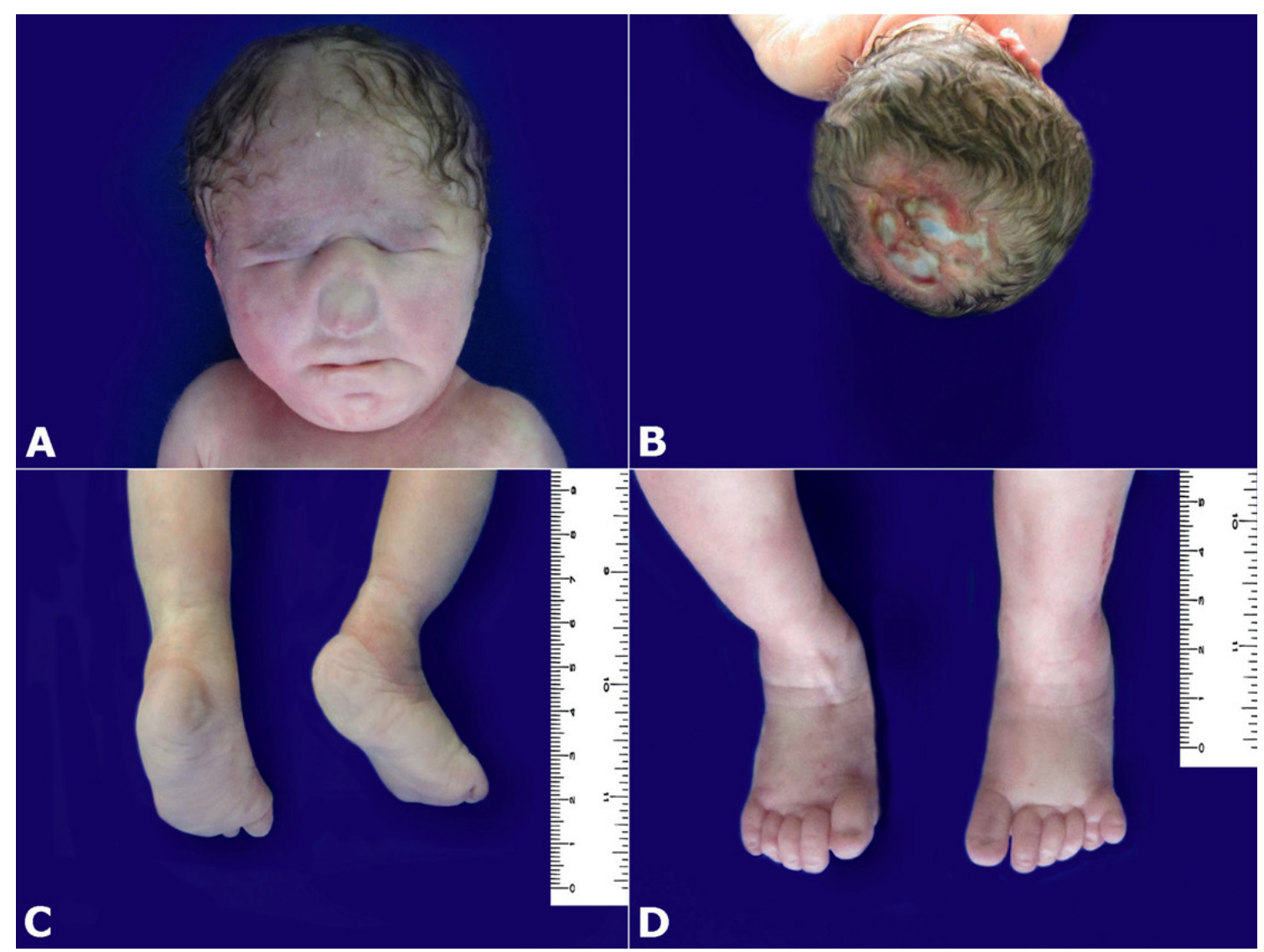

Figure 1 - External Examination of the newborn. A - Proboscis, microcephaly, ocular hypotelorism, microstomia; B - Aplasia cutis on the scalp; C - Proeminent heels; D - Polydactyly on left foot with short hallux and hypoplastic nails.

was evident with the findings of left ventricle hypoplasia, atrial septal defect at fossa ovalis, membranous sub-valvar ventricular septal defect, tricuspid valve dysplasia, hypoplasia of the mitral and aortic valves, enlarged pulmonary artery, and double-outlet right ventricle, which was dilated (Figure 3).

The pulmonary microscopic examination showed evidence of bronchial tree malformations, characterized by enlarged bronchi with irregular lumen depicting a geographic pattern (Figure 4A). Microscopic examination of the lungs showed the presence of hyaline membrane, alveolar hemorrhage, and signs of meconial aspiration (Figure 4B).

Microscopic evidence of prematurity was found in the thyroid, spleen, and liver with extramedullary hematopoiesis and kidneys showing nephrogenic zones. All theses findings were compatible with the 31-week gestational age.

The autopsy findings and the karyotyping of amniotic fluid cells are compatible with Patau's syndrome (trisomy 13) expressing midline malformation.

\section{DISCUSSION}

Patau et al. ${ }^{1}$ first recognized the relationship between the trisomy of chromosome 13 and a clinical syndrome in 1960. About $80 \%$ of Patau's syndrome cases are regular trisomies arising from nondisjunction at the first or second meiotic division. A small proportion of cases have a translocation either arising de novo or inherited from a parent who carries a balanced translocation. ${ }^{2}$ The newborn's prognosis is often poor mainly because of the neurological and cardiac malformations.

Trisomy 13 accounts for up to $75 \%$ of cases of patients with holoprosencephaly (HPE) ${ }^{3}$ due to all chromosomal anomalies (including cryptic rearrangements). Up to $20 \%$ of those cases also have triploidy. ${ }^{4}$

HPE refers to a spectrum of central nervous system (CNS) malformations that result 

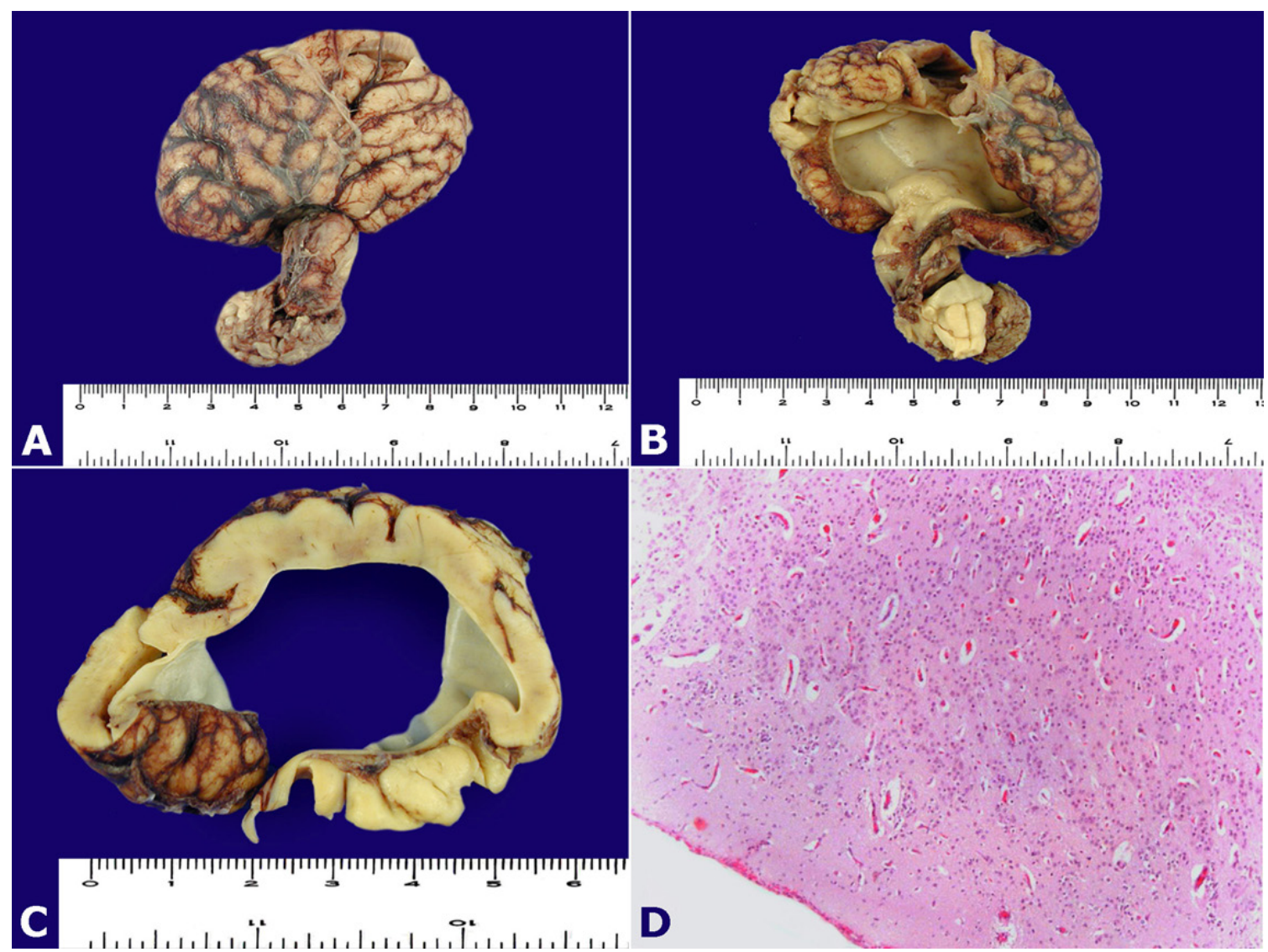

Figure 2-Alobar holoprosencephaly. A - Top view; B - Bottom view; C - Coronal section; D - Photomicrography of cerebral cortex showing migration defect (200x).
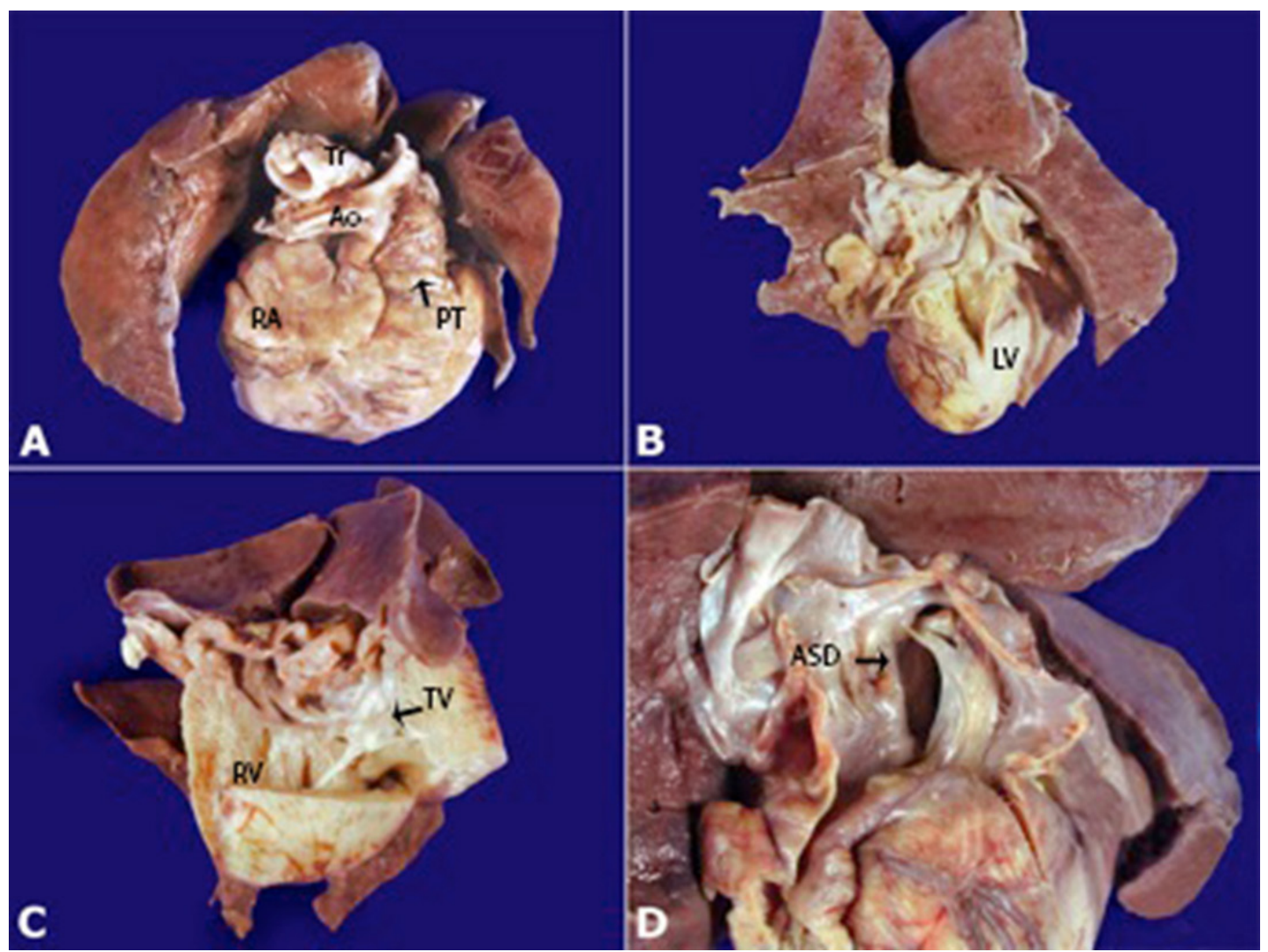

Figure 3 - Hypoplastic left heart syndrome. A - Dilated right atrial appendage, large pulmonary artery and small ascending aorta; B - Hypoplastic left heart ; C - Dysplasia of tricuspid valve; D - Atrial septal defect at fossa ovalis. $A o=$ aorta; $A S D=$ atrial septal defect; $L V=$ left ventricle; $P T=$ pulmonary trunk; $R A=$ right atrium; $\mathrm{RV}=$ right ventricle; $\mathrm{Tr}=$ trachea; $\mathrm{TV}=$ tricuspid valve. 


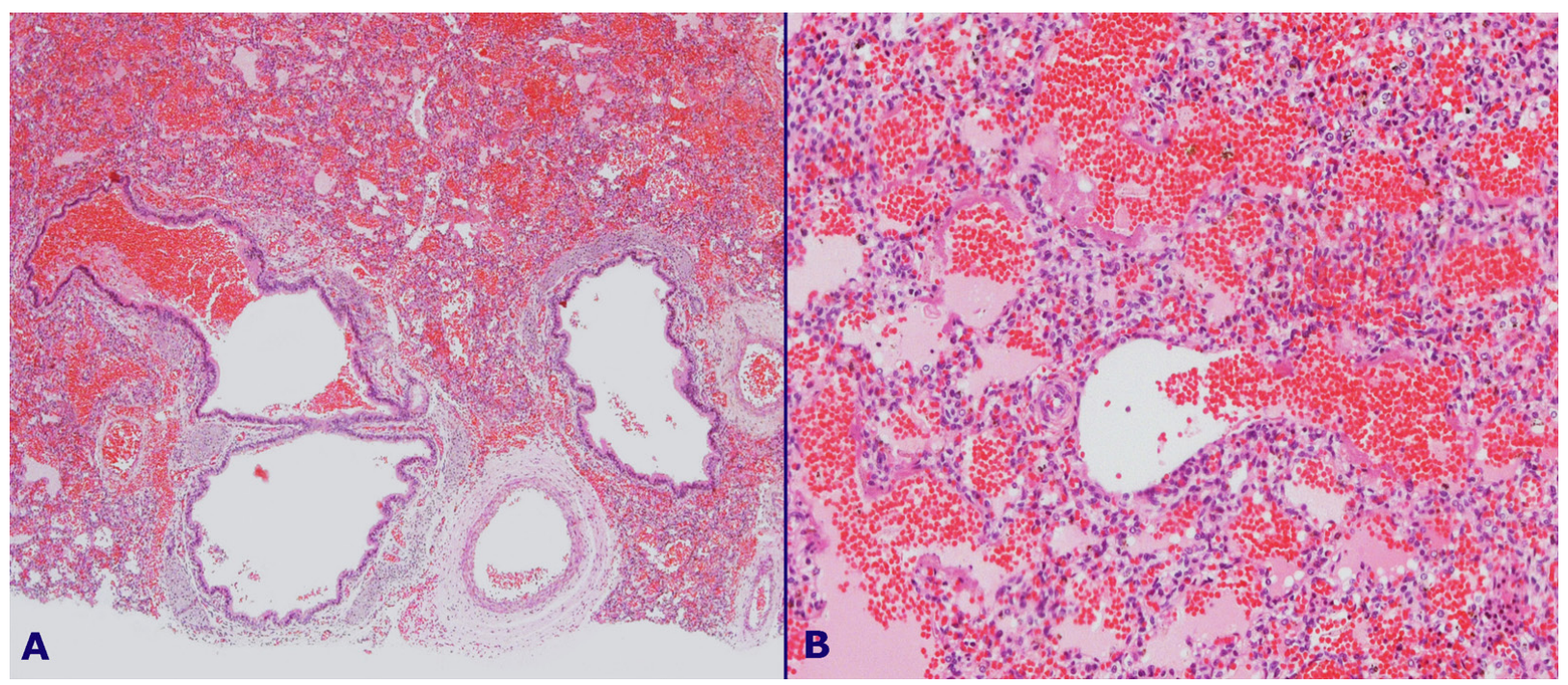

Figure 4 - Bronchial tree malformation. A - Bronchi showing an irregular volume and a geographical pattern (100x); B - Alveolar hemorrhage, hyaline membrane and signs of meconium aspiration (200x).

from a primary defect in the normal inducing and molding of the rostral neural tube during early embryogenesis. It is usually considered to be the result of prosencephalon cleavage failure, which usually occurs during the fifth or sixth week of gestation..$^{3,5}$

In 1882, Kundrat ${ }^{6,7}$ reported the first description of neuropathological HPE, recognizing the aplasia of bulbs and olfactory tracts as a common denominator in this group of malformations, which he named arhinencephaly. In 1959, after Yakovlev's ${ }^{8}$ studies, the term arhinencephaly was considered erroneous. In 1963, DeMyer and Zeman, ${ }^{9}$ followed by DeMyer et al. ${ }^{10}$ in 1964 , named this malformation as holoprosencephaly, studying two patients who presented with orbital hypotelorism, flat nose, bilateral cleft lip, and cleft palate. They believed that HPE was the generic-descriptive term for the teratogenic spectrum. Subsequently, Robain and Gorce (1972) ${ }^{11}$ and Jellinger and Gross (1973) ${ }^{12}$ introduced the concept of the defects of the midline..$^{6,12,13}$ Based on the gross examination of the degree of non-hemispherical separation, DeMyer and Zeman $(1963)^{9}$ also proposed a classification of HPE into three types, namely alobar, semilobar, and lobar. This classification is based on the presence or absence of the inter-hemispheric fissure and the extent of separation of both hemispheres. In 1993, Barkovich and Quint ${ }^{14}$ identified a mild variant of HPE, called syntelencephaly or middle interhemispheric variant, indicating that the HPE apparently represents a continuum of cerebral malformations without a cutting point that makes a clear distinction between the different subcategories.
Because of the interrelated development of the primitive brain and underlying mesodermal structures, patients often exhibit specific craniofacial anomalies, including midline facial clefts, cyclopia, and nasal abnormalities, in addition to brain "holosphere" or the undivided prosencephalic vesicle. Particularly in the severe forms of HPE, the same failure of induction of midline structures may be reflected in midline facial characteristics.

The pathogenesis of this disorder has been elucidated in a number of recent experimental studies on the neural tube and the identification of various gene mutations. Four genes, related to brain development, were detected and their chromosomal regions have been studied: HPE1, HPE2, HPE3, and HPE4. ${ }^{15}$ The cases used in each of these chromosomal mapping studies, although few, exhibit a broad spectrum of HPE phenotypes, reflecting the complexity and heterogeneity involved in its etiology.

This malformation occurs in families, although the degree of involvement among affected individuals can vary widely within the same family. The incidence of HPE is about $0.48-0.88$ per 10,000 live births with normal chromosomes. ${ }^{3}$ However, there is a high rate of fetal wastage, with the incidence of HPE in intrauterine demise estimated at 40 per $10,000 .^{3}$

Several maternal/environmental factors, including diabetes and ethanol consumption have been associated with HPE sequence. ${ }^{3,5}$ Experimental ethanol exposure in rats and monkeys can produce facial and CNS abnormalities similar to HPE. ${ }^{3}$ Plants, such as Veratrum californicum, 
which contain the alkaloid cyclopamine, can induce HPE in rodents, rabbits, and chickens. ${ }^{3}$ Similarly, the administration of inhibitors of cholesterol biosynthesis in rats resulted in facial and skeletal abnormalities, pituitary agenesis, and HPE. ${ }^{3}$

In human cases of HPE, when there is no maternal diabetes or fetal alcohol exposure, a genetic cause in conjunction with other systemic abnormalities has been recognized. The most common chromosomal abnormality in patients with HPE is trisomy of chromosome 13 , as in this case report, which is reported in $24-45 \%$ of newborns with this trisomy. In addition to trisomy 13 , several other chromosomal abnormalities, including trisomy 18 , trisomy $13-15$, trisomy $13-15$ mosaicism, ring chromosome 13 or 18 , and chromosomal deletion 13 or 18, have been identified in patients with HPE. This malformation was also reported in Klinefelter syndrome ${ }^{16}$ and trisomy $10 .{ }^{17}$

The most serious expression of classic HPE occurs in alobar HPE. In this form, the brain is usually smaller than normal and consists of one holosphere without interhemispheric fissure, sagittal sinus, or falx cerebri, exhibiting the shape of pancake, cup, or ball. ${ }^{13,18}$ In the upper posterior view of the brain, the telencephalon is not divided, usually shows as a horseshoe shape, with a single ventricle in its lower portion.

In the semilobar form of HPE, a decreased encephalic weight is also observed, but not as much as in the alobar form. The main feature consists of an incomplete interhemispheric fissure and falx cerebri. The gyri pattern remains abnormal. ${ }^{10}$ The frontal lobes may be underdeveloped with rudimentary temporal horns and a hippocampus that is not completely formed. The Sylvian fissure is abnormally displaced to the front. In a perpendicular section, the septum pellucidum is absent. ${ }^{7}$

In the lobar form of HPE, the interhemispheric fissure is observed along the entire midline. The cerebral lobes are fully developed, particularly the frontal lobes. In coronal sections, the cortex crosses the midline at the level of the median fissure, establishing a bridge between both hemispheres. The frontal horns of the lateral ventricles are present, although dysplastic. ${ }^{7}$

All theseabnormalities regarding hemispheric cleavage are associated with aplasia of olfactory bulbs and tracts, except in the lobar form, where olfactory bulbs can be identified. ${ }^{7}$
On microscopic examination, the cytoarchitecture of the cerebral cortex may be normal, although displaced from its usual location. However, some cases may exhibit significant disorganization, possibly representing: (a) abnormal cell migration; (b) secondary injury to the cerebral cortex; or (c) abnormality in connections into and out of the cerebral cortex. ${ }^{3,7}$ Pial glia-neural heterotopy can form a "crust" on the brain surface, most commonly seen in the late stage of pregnancy and the postnatal period. ${ }^{3}$

The hippocampus is identifiable on microscopy, although it is often displaced showing an incomplete or abnormal development. The histopathology of the basal ganglia and thalamus varies with the severity of the hemispherical malformation. The septum pellucidum is generally absent in all forms. At microscopy, the cerebellum may show focal cortical disorganization, heterotopy, or both, especially in the context of trisomy 13 and other cytogenetic abnormalities. Brain stem abnormalities are limited to hypoplasia or the absence of the corticobulbar and corticospinal tracts, as well fusion of the colliculi or peduncles at the midbrain level.

Newborns who survive with the severe holoprosencephalic variant (alobar HPE), usually have severe mental retardation and often present hard-to-control epilepsy. They may present hypothalamic dysfunction with diabetes insipidus, poikilothermy, and inappropriate secretion of antidiuretic hormone. Patients with an intermediate form of HPE and isolated arhinencephaly may have a normal survival rate with very limited clinical deficits, such as cognitive delay and epilepsy.

\section{CONCLUSION}

Several neuropathological studies have shown that malformations of the holoprosencephalic sequence can be multiple and complex, involving multiple anatomic sites. Therefore a thorough morphological examination is required to better delineate underlying diseases as well as pathophysiological mechanisms. It is also essential that genetic counseling be improved, given the wide phenotypic variability, genetic heterogeneity, and risk of recurrence even in apparently sporadic cases. Recent advances in the study of the pathogenesis and genetics of HPE have shown that it is a continuous spectrum of lesions. These advances may contribute to further reclassification 
of these cerebral lesions and enable HPE to be better understood.

\section{REFERENCES}

1. Patau K, Therman DG, Cameron AH, Wolff, OH. A new trisomic syndrome. Lancet. 1969;i:787-9.

2. Boyd PA, Keeling JW. Congenital abnormalities: prenatal diagnosis and screening. In: Keeling JW, Khong TY, editors. Fetal and neonatal pathology. 4th ed. London: Springer; 2007. p 123-61. http://dx.doi.org/10.1007/978-1-84628-743-5_6

3. Folkerth RD, Lidov HCG. Congenital malformations, perinatal diseases, and phacomatoses. In: Prayson RA, editor. Neuropathology. 2nd ed. Philadelphia: Elsevier; 2012. p. 96-182.

4. Solomon B, Rosenbaum KN, Meck JM, Muenke M. Holoprosencephaly due to Numeric Chromosome Abnormalities. Am J Med Genet Part C (Seminars in Medical Genetics). 2010;154C:46-8. PMid:20104610 PMCid:2815046. http://dx.doi.org/10.1002/ajmg.c.30232

5. Ong S, Tonks A, Woodward ER, Wyldes MP, Kilby MD. An epidemiological study of holoprosencephaly from a regional congenital anomaly register: 1995-2004. Prenat Diagn. 2007;27:340-7. PMid:17286306. http://dx.doi. org/10.1002/pd.1677

6. Kundrat H. Arhinencephalie als typische Art von Missbidung. Graz: von Leuschner and Lubensky; 1882.

7. Marcorelles P, Laquerriere A. Neuropathology of holoprosencephaly. Am J Med Genet Semin Med Genet. 2010;154C:109-19. http://dx.doi.org/10.1002/ ajmg.c.30249 http://dx.doi.org/10.1002/ajmg.c.30249

8. Yakovlev PL. Pathoarchitectonic studies in brain malformations. III. Arhinencephalies (hototelencephalies). J Neuropathol Exp Neurol. 1959;18:22-55. PMid:13621243. http://dx.doi.org/10.1097/00005072-195901000-00003

9. DeMyer WE, Zeman W. Familia alobar holoprosencephaly (arhinencephaly) with median cleftlip and palate: Clinical, electroencephalographic, and nosologic considerations.
Confin Neurol. 1963;23:1-36. PMid:14026941. http://dx.doi. org/10.1159/000104278

10. DeMyer WE, Zeman W, Palmer C. The face predicts the brain, diagnostic significance of medial facial anomalies from holoprosencephaly (arhinencephaly). Pediatrics. 1964;34:256-63. PMid:14211086.

11. Robain O, Gorce F. Arhinencephalia. Clinical, anatomical and etiological study of 13 cases. Arch Fr Pediatr. 1972;29:861- 79. PMid:4657334.

12. Jellinger K, Gross H. Congenital telencephalic midline defects. Neuropediatrie. 1973;4:446-452. PMid:4801896. http://dx.doi.org/10.1055/s-0028-1091760

13. Jellinger K, Gross $H$, Kaltenback E, Grisold W. Holoprosencephaly and agenesis of the corpus callosum: Frequency of associated malformations. Acta Neuropathol. 1981; 55:1-10. PMid:7348001. http://dx.doi. org/10.1007/BF00691523

14. Barkovich AJ, Quint DJ. Middle interhemispheric fusion: an unusual variant of HPE. AJNR Am J Neuroradiol. 1993;14:431-40. PMid:8456724.

15. Olsen CL, Hughes JP, Youngblood LG, StimacSharpe M. Epidemiology of holoprosencephaly and phenotypic characteristics of affected children: New York State, 1984-1989. Am J Med Genet. 1997;73:21726. http://dx.doi.org/10.1002/(SICI)10968628(19971212)73:2<217::AID-AJMG20>3.0.CO;2-S

16. Armbruster-Moraes E, Schultz R, Brizot MDL, Miyadahira S, Zugaib M. Holoprosencephaly in a Klinefelter fetus. Am J Med Genet. 1999;85:511-2. http://dx.doi.org/10.1002/(SICI)10968628(19990827)85:5<511::AID-AJMG15>3.0.CO;2-S

17. Brizot ML, Schultz R, Patroni LT, Lopes LM, ArmbrusterMoraes E, Zugaib M. Trisomy 10: ultrasound features and natural history after first trimester diagnosis. Prenat Diagn. 2001;21:672-5. PMid:11536269. http://dx.doi. org/10.1002/pd.129

18. Cohen MM. Holoprosencephaly: clinical, anatomic, and molecular dimensions. Birth Defects Res A Clin Mol Teratol. 2006;76:658-73. PMid:17001700. http://dx.doi. org/10.1002/bdra.20295

\section{Conflict of interest: None}

Submitted on: $2^{\text {nd }}$ March 2013

Accepted on: $6^{\text {th }}$ June 2013

Correspondence: Departamento de Patologia

Hospital das Clínicas - Faculdade de Medicina da Universidade de São Paulo

Av. Dr. Enéas Carvalho de Aguiar, 155 - 10. andar - São Paulo/SP - Brazil

CEP: 05503-000 - Phone: +55 (11) 2661.6092

E-mail: costaandressa@yahoo.com.br 